\title{
Manage Storm Water by Using Porous Pavement
}

\author{
Mr.Dipanjan Mukherjee \\ M.Tech (Pursuing) Civil Engineering (Transportation Engineering) National Institute Of Technology; \\ Silchar, Assam, India
}

\begin{abstract}
As cities grow, the amount of impermeable surfaces - those that do not allow water to infiltrate into the ground-increases Examples of impervious surfaces are asphalt roads, concrete sidewalks, parking lots, building roofs, and areas of highly compacted soils such as in subdivisions. If not properly managed, the storm water runoff produced by these impermeable surfaces can have negative effects on nearby surface waters. When waters from storm events do not infiltrate the soil, the storm water management system, consisting of storm water structures and pipes, quickly directs them to streams, rivers, and lakes. Such increases in storm water runoff can have detrimental effects on nearby lands and receiving streams resulting in flooding, increased peak flows, groundwater or stream base flow reductions, increased stream velocities and stream bank erosion, increased water temperatures, and reduced water quality. Storm water must be managed in such a way as to prevent or minimize these negative impacts from urban growth. One method of storm water management is to reduce runoff by increasing infiltration through the use of permeable or pervious pavement. Permeable pavement allows storm water to percolate through the pavement and infiltrate the underlying soils thereby reducing runoff from a site, unlike standard pavement which prohibits infiltration. In previous concrete, carefully controlled amounts of water and cementations materials are used to create a paste that forms a thick coating around aggregate particles. Permeable pavement looks similar to standard asphalt or concrete except void spaces are created by omitting fine materials. Compacted gravel is not considered permeable pavement. Permeable paving surfaces keep the pollutants in place in the soil or other material underlying the roadway, and allow water seepage to groundwater recharge while preventing the stream erosion problems. However, some properties of most permeable pavements limit their applicability. Permeable pavements are not generally used in applications where high traffic loads, in terms of volume and weight, and/or high rates of speed are encountered. Their use should be limited to pedestrian and light to medium vehicle traffic. Greenways, sidewalks, driveways.
\end{abstract}

Key Word: Construction, Types, Advantages, Disadvantages, Maintenances

\section{Introduction:}

Pervious pavement is made of either pervious asphalt or pervious concrete. Both materials resemble conventional asphalt and concrete, but have more air spaces that allow water to pass through the pavement into a reservoir base of crushed aggregate, then infiltrate into the ground. Pervious pavement is designed to accept precipitation only and is typically thicker than traditional concrete to support the same loads. Pervious asphalt consists of coarse stone aggregate and asphalt binder, with very little fine aggregate. Water percolates through the small voids left in the finished asphalt. A thick layer of gravel underneath allows water to drain through quickly. Pervious asphalt looks similar to conventional asphalt, although with rougher surface. Pervious concrete consists of specially formulated mixtures of Portland cement open-graded coarse aggregate, and water. It has enough void space to allow rapid percolation of water and resembles exposed aggregate concrete. Pervious concrete pavement is a unique and effective means to address important environmental issues and support green, sustainable growth. By capturing storm water and allowing it to seep into the ground, porous concrete is instrumental in recharging groundwater, reducing storm water runoff, and meeting U.S. Environmental Protection Agency (EPA) storm water regulations.

\section{Construction:}

In pervious concrete, carefully controlled amounts of water and cementations materials are used to create a paste that forms a thick coating around aggregate particles. A pervious concrete mixture contains little or no sand, creating a substantial void content. Using sufficient paste to coat and bind the aggregate particles together creates a system of highly permeable, interconnected voids that drains quickly. Typically, between $15 \%$ and $25 \%$ voids are achieved in the hardened concrete, and flow rates for water through pervious concrete are typically around $480 \mathrm{in} . / \mathrm{hr}\left(0.34 \mathrm{~cm} / \mathrm{s}\right.$, which is $5 \mathrm{gal} / \mathrm{ft}^{2} / \mathrm{min}$ or $\left.200 \mathrm{~L} / \mathrm{m}^{2} / \mathrm{min}\right)$, although they can be much higher. Both the low mortar content and high porosity also reduce strength compared to conventional concrete mixtures, but sufficient strength for many applications readily achieved. Soil Permeability is Recommended Between 0.25-3.0 Inches per Hour. Recommended Drainage Time of 24-48 Hours. Sub-Drains Should be Used 
Where Proper Drainage May be an Issue to Minimize Frost Damage Most Appropriate for use with Low-Use Roadways and Parking Lots-Without a modified Asphalt Binder. 3-5 Feet of Vertical Separation is Needed from Seasonal High Groundwater.

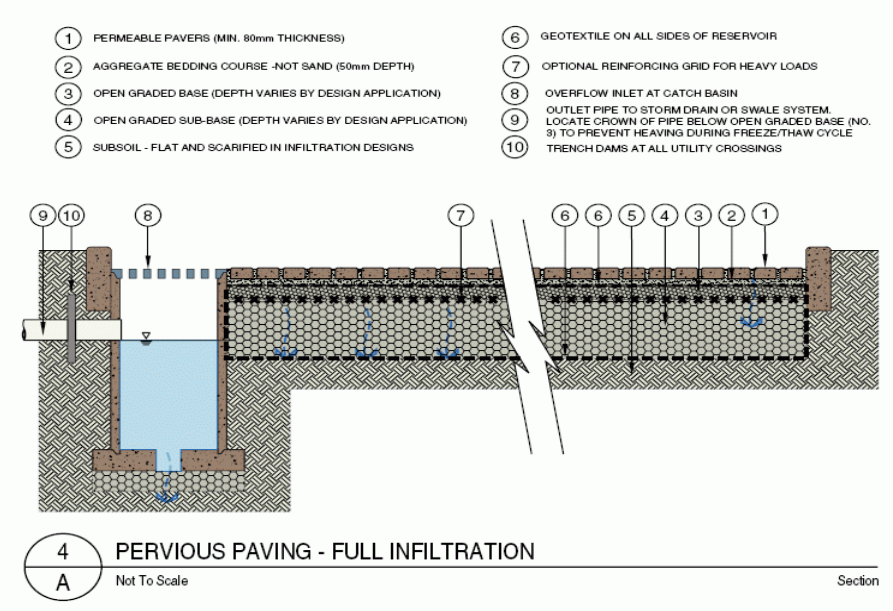

Figure 1 Pervious pavement construction

\section{Benefits:}

1. Permeable pavements may give urban trees the rooting space they need to grow to full size.

2. A "structural-soil" pavement base combines structural aggregate with soil; a porous surface admits vital air and water to the rooting zone.

3. This integrates healthy ecology and thriving cities, with the living tree canopy above, the city's traffic on the ground, and living tree roots below.

4. Quantity and Flood Control.

5. Water Quality Treatment-

Permeable paving surfaces keep the pollutants in place in the soil or other material underlying the roadway, and allow water seepage to groundwater recharge while preventing the stream erosion problems. They capture the heavy metals that fall on them, preventing them from washing downstream and accumulating inadvertently in the environment. In the void spaces, naturally occurring micro-organisms digest car oils, leaving little but carbon dioxide and water.

6. Recharges Groundwater to Underlying Aquifers

7. Allows for Reduction of Storm water Infrastructure (Piping, Catch-Basins, RetentionPonds, Curbing, etc.)

8. Suitable for Cold-Climate Applications, Maintains Recharge Capacity When Frozen,

9. Allows for Reduced Salt and Sand Usage Due to Low/No Black Ice Development.

10. Maintains Traction While Wet.

11. Reduced Spray from Traveling Vehicles, Reduced Roadway Noise.

12. Extended Pavement Life Due to Well Drained Base and Reduced Freeze-Thaw.

\section{Disadvantages:}

\section{- Runoff volumes}

Permeable pavements are designed to replace Effective Impervious Areas (EIAs), not to manage storm water from other impervious surfaces on site. Use of this technique must be part of an overall on site management system for storm water, and is not a replacement for other techniques.

\section{- Pollutant load}

Highly contaminated runoff can be generated by some land uses where pollutant concentrations exceed those typically found in storm water. These "hot spots" include commercial nurseries, recycling facilities, fueling stations, industrial storage, marinas, some outdoor loading facilities, public works yards, hazardous materials generators (if containers are exposed to rainfall), vehicle service and maintenance areas, and vehicle and equipment washing and steam cleaning facilities. Since porous pavement is an infiltration practice, it should not be applied at storm water hot spots due to the potential for groundwater contamination. 


\section{- Weight and traffic volumes}

Reference sources differ on whether low or medium traffic volumes and weights are appropriate for porous pavements. For example, around truck loading docks and areas of high commercial traffic, porous pavement is sometimes cited as being inappropriate. However, given the variability of products available, the growing number of existing installations in North America and targeted research by both manufacturers and user agencies, the range of accepted applications seems to be expanding. Some concrete paver companies have developed products specifically for industrial applications. Working examples exist at fire halls, busy retail complex parking lots, and on public and private roads.

\section{Maintenance :}

Some permeable pavements require frequent maintenance because grit or gravel can block the open pores. This is commonly done by industrial vacuums that suck up all the sediment. If maintenance is not carried out on a regular basis, the porous pavements can begin to function more like impervious surfaces. With more advanced paving systems the levels of maintenance needed can be greatly decreased, elastomerically bound glass pavements requires less maintenance than regular concrete paving as the glass bound pavement has $50 \%$ more void space. It is important to control site erosion and sedimentation of the pavement surface prevents clogging and maintains permeability. Cleaning or vacuuming the surface once or twice a year maintains porosity. Properly installed pervious paving systems last more than 20 years.

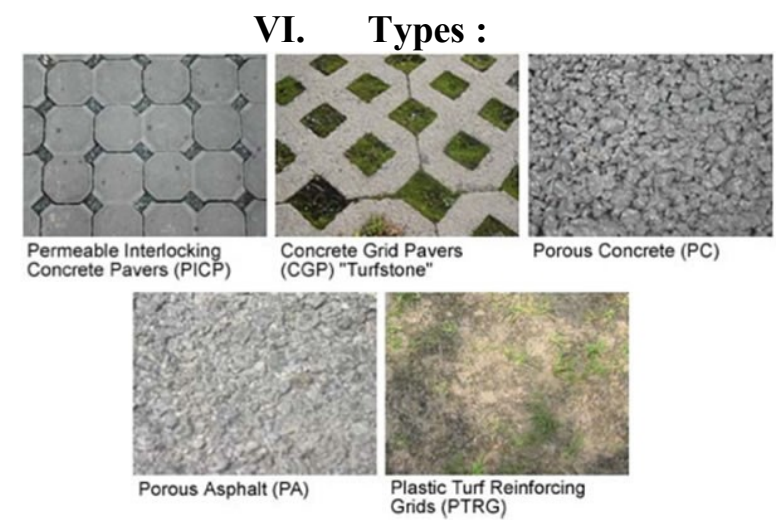

Figure 2 various types of pervious pavements

\section{Conclusion :}

Some estimates put the cost of permeable paving at two to three times that of conventional asphalt paving. Using permeable paving, however, can reduce the cost of providing larger or more storm water .In addition, the off-site environmental impact costs of not reducing on-site storm water volumes and pollution have historically been ignored or assigned to other groups (local government parks, public works and environmental restoration budgets, fisheries losses, etc). is important to control site erosion and sedimentation of the pavement surface prevent clogging and maintain permeability. Cleaning or vacuuming the surface once or twice a year maintains porosity. Properly installed pervious paving systems last more than 20 years. Permeable pavement can be installed in most places that conventional concrete or asphalt pavement is presently used. However, some properties of most permeable pavements limit their applicability. Permeable pavements are not generally used in applications where high traffic loads, in terms of volume and weight, and/or high rates of speed are encountered. Their use should be limited to pedestrian and light to medium vehicle traffic. Greenways, sidewalks, driveways, and overflow parking lots are ideal locations. Permeable pavement has also been used in agricultural facilities such as horse washing pads. To reduce the potential for groundwater contamination, consideration should be given to the pollutant loads carried in the storm water runoff because permeable pavement promotes infiltration. Permeable pavement should not be used near "hotspots" or areas generating significant concentrations of pollutants. Examples of such hotspots include vehicle service areas, industrial chemical storage facilities, and gas stations.

\section{References:}

[1]. PERVIOUS PAVEMENT - Environmental services city of Portland. www.CleanRiverRewards.com

[2]. Permeable Pavement for Storm water Management- Carmen T. Agouridis, Jonathan A. Villines, and Joe D. Luck, Biosystems and Agricultural Engineering

[3]. Permeable Pavement Fact Sheet Information for Howard County, Maryland Homeowners, University of Maryland, Extension.

[4]. Porous Asphalt Pavement for Storm water Management, The UNH Storm water Centre

[5]. http://en.wikipedia.org/wiki/Permeable_paving 